\title{
Adipocitocinas: uma nova visão do tecido adiposo
}

\author{
Adipokines: a new view of adipose tissue
}

Daniella Esteves Duque GUIMARÃES'

Fátima Lúcia de Carvalho SARDINHA ${ }^{1}$

Daniella de Moraes MIZURINI ${ }^{1}$

Maria das Graças TAVARES DO CARMO'

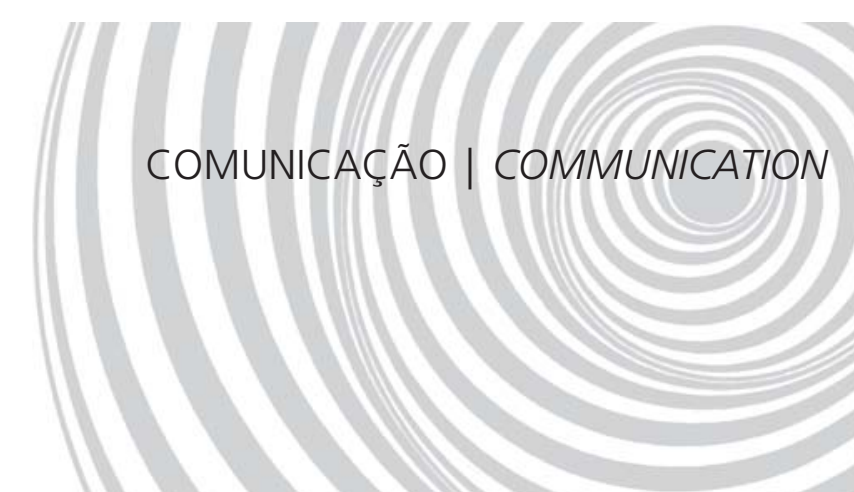

Maria das Graças TAVARES DO CARMO

RESUMO

A identificação da leptina, hormônio secretado pelos adipócitos, cujo efeito sobre o sistema nervoso simpático e a função endócrina confere participação ativa no controle do dispêndio energético, bem como do apetite, acrescentou às funções do tecido adiposo no organismo humano o papel de órgão multifuncional, produtor e secretor de inúmeros peptídeos e proteínas bioativas, denominadas adipocitocinas. Alterações na quantidade de tecido adiposo, como ocorrem na obesidade, afetam a produção da maioria desses fatores secretados pelos adipócitos. Ainda que essas alterações estejam freqüentemente associadas às inúmeras disfunções metabólicas e ao aumento do risco de doenças cardiovasculares, permanece sob investigação o envolvimento do tecido adiposo no desenvolvimento dessas complicações, considerada a sua função endócrina. As concentrações de várias adipocitocinas elevam-se na obesidade e têm sido relacionadas à hipertensão (angiotensinogênio), ao prejuízo da fibrinólise (inibidor do ativador de plasminogênio-1) e à resistência à insulina (proteína estimuladora de acilação, fator de necrose tumoral- $\alpha$, interleucina- 6 e resistina). De outro modo, leptina e adiponectina têm efeitos sobre a sensibilidade à insulina. Na obesidade, a resistência insulínica também está relacionada à resistência à leptina e aos teores plasmáticos reduzidos de adiponectina. Leptina e adiponectina ainda exercem efeitos orgânicos adicionais distintos: frente à participação da leptina no controle da ingestão alimentar, a adiponectina apresenta potente ação anti-aterogênica. Algumas drogas utilizadas no controle do diabetes elevam a produção endógena de adiponectina, em roedores e humanos, indicando que o desenvolvimento de novos medicamentos com alvo nas adipocitocinas pode representar uma alternativa terapêutica de prevenção da resistência insulínica e da aterosclerose em indivíduos obesos.

Termos de indexação: adipocitocinas; aterosclerose; obesidade; resistência à insulina; tecido adiposo.

\section{A B S T R A C T}

Leptin is a hormone secreted by adipocytes whose effect on the sympathetic nervous system and endocrine function confers active participation in the control of energy expenditure and appetite. Its identification added to the fat tissues in the human body the role of a multifunctional organ that produces and secretes a

\footnotetext{
${ }^{1}$ Universidade Federal do Rio de Janeiro, Centro de Ciências da Saúde, Instituto de Nutrição Josué de Castro. Av. Brig. Trompowski, s/n., Bloco J, $2^{\circ}$ andar, 21941-590, Rio de Janeiro, RJ, Brasil. Correspondência para/Correspondence to: M.G. TAVARES DO CARMO. E-mail:<tcarmo@editema.com.br>.
} 
550 | D.E.D. GUIMARÃES et al.

number of bioactive peptides and proteins, called adipocytokines. Changes in the amount of fat tissue, such as the ones that occur in obesity, affect the production of most of these factors secreted by adipocytes. Even if these changes are frequently associated with many metabolic disorders and increased risk for cardiovascular diseases, the role of fat tissue in the development of these complications, considered its endocrine function, continue to be investigated. The concentration of various adipocytokines increase in obesity and have been associated with hypertension (angiotensinogen), fibrinolysis impairment (plasminogen activator inhibitor-1) and insulin resistance (protein that stimulates acylation, tumor necrosis factor-alpha, interleukine-6 and resistin). On the other hand, leptin and adiponectin affect insulin sensitivity. In obesity, insulin resistance is also associated with leptin resistance and reduced plasma levels of adiponectin. Leptin and adiponectin still have complementary and distinct organic functions: adiponectin has potent antiatherogenic activity while leptin participates in the control of food intake. Some medications used to control diabetes increase adiponectin production in rodents and humans, suggesting that the development of new medications that target the adipocytokines can represent a new therapeutic alternative to prevent insulin resistance and atherosclerosis in obese individuals.

Indexing terms: adipokines; atherosclerosis; obesity; insulin resistance; adipose tissue.

\section{N T R O D U ÇÃ O}

Durante muitos anos o tecido adiposo foi considerado o mais importante órgão de armazenamento de energia do organismo humano. $\mathrm{O}$ excesso de energia consumido é convertido em moléculas de triacilgliceróis, sob ação do hormônio insulina, enquanto que na situação de restrição energética, os estoques de energia são rapidamente mobilizados, sob a influência das catecolaminas e outros hormônios lipolíticos ${ }^{1,2}$.

À caracterização do tecido adiposo, fundamentalmente como um órgão de armazenamento de energia, vêm sendo sendo acrescidas, nos últimos 10 anos, propriedades distintas. A identificação da leptina, hormônio secretado pelos adipócitos, cujo efeito sobre o sistema nervoso central e a função endócrina, confere participação ativa no controle do dispêndio energético bem como do apetite, acrescentou às clássicas e reconhecidas funções do tecido adiposo no organismo humano, o papel de órgão multifuncional, produtor e secretor de inúmeros peptídeos e proteínas bioativas, denominadas adipocitocinas. Este conceito emergente define para o tecido adiposo importante função endócrina, mantendo intensa comunicação com os demais órgãos e sistemas orgânicos².

As adipocitocinas influenciam uma variedade de processos fisiológicos, entre eles, o controle da ingestão alimentar, a homeostase energética, a sensibilidade à insulina, a angiogê- nese, a proteção vascular, a regulação da pressão e a coagulação sanguínea. Alterações na secreção de adipocitocinas, conseqüentes à hipertrofia e/ou hiperplasia dos adipócitos, poderiam constituir situação relacionada à gênese do processo fisiopatológico da obesidade e suas complicações '.

O tecido adiposo, enquanto órgão secretor, apresenta distintas peculiaridades, entre elas: 1) constitui tecido de ampla e variada distribuição orgânica, cuja característica compartimentalização individual, nem sempre apresenta conexão entre si. O(s) mecanismo(s) envolvido(s) com a atividade secretora dos adipócitos permanece $(\mathrm{m})$ sob investigação, existindo dúvidas acerca dos processos humoral e/ou neural relacionados; 2) adipócitos maduros, pré-adipócitos, fibroblastos e macrófagos, representam os diferentes tipos de células que constituem o tecido adiposo e participam da sua função endócrina; 3) a capacidade metabólica do tecido adiposo varia em função da sua localização, subcutânea ou visceral, podendo contribuir de forma mais ou menos intensa para a secreção de adipocitocinas específicas ${ }^{3}$.

A literatura ainda oferece limitada informação a respeito dos mecanismos que explicam a associação da obesidade com o diabetes e outras doenças metabólicas e vasculares. Credita-se à elucidação das funções fisiológicas das adipocitocinas, a possibilidade de ampliar a compreensão dos referidos mecanismos, podendo representar avanço importante na prevenção e terapêutica daquelas doenças. 
A presente comunicação pretende descrever as principais ações de algumas adipocitocinas relacionadas com a homeostase energética (leptina, adiponectina, resistina, proteína estimuladora de acilação (ASP), fator de necrose tumoral (TNF- $\alpha$ ) e interleucina-6 (IL-6) e o sistema vascular (PAl-1 e angiotensinogênio). Foi realizada revisão criteriosa da literatura pertinente, buscando identificar as bases científicas que respaldam a caracterização do tecido adiposo branco como órgão endócrino. Foi utilizada a base de dados PubMed, incluindo estudos publicados entre 1994 e 2005, referentes às adipocitocinas secretadas pelo tecido adiposo e sua relação com o estabelecimento de doenças crônicas não transmissíveis. Buscou-se identificar estudos clínicos e experimentais com diferentes bases metodológicas. Os principais termos utilizados para a busca foram: adipose tissue, adipokines, leptin, adiponectin, resistin, TNF- $\alpha$, obesity, insulin resistance, atherosclerosis.

\section{ADIPOCITOCINASE}

\section{METABOLISM O ENERGÉTICO}

\section{Leptina}

A leptina (do grego Leptos = magro) é uma proteína de 167 aminoácidos, produto do gene $O b$, que foi inicialmente clonado e seqüenciado em camundongos e que se expressa principalmente no tecido adiposo branco. O gene Ob está presente, bem como sua seqüência está bastante conservada, em diversas espécies de vertebrados, incluindo o rato e o homem. Os teores circulantes são proporcionais à massa adiposa, apresentando-se elevados em animais obesos ${ }^{4}$. A identificação de uma mutação no gene $O b$ nos camundongos geneticamente obesos da linhagem ob/ob (da qual deriva o nome deste locus gênico: $O b$ ou $L E P$ ) constituiu um marco no estudo do controle fisiológico do balanço energético e da fisiopatologia da obesidade.

Em 1997, Montague et al. ${ }^{5}$, ao estudarem duas crianças portadoras de obesidade mórbida que apresentavam concentrações séricas reduzidas de leptina, encontraram uma mutação envolvendo uma deleção no códon 133 do locus Ob. A obesidade severa presente nesses dois indivíduos, congenitamente deficientes em leptina, forneceu a primeira evidência genética de que essa adipocitocina seria um importante regulador do balanço energético na espécie humana. Entretanto, a procura de mutações do gene $O b$ em humanos obesos, portadores de obesidade simples, tem levado a resultados negativos ${ }^{6}$, muito embora mais recentemente, Faroogi et al. ${ }^{7}$ tenham verificado que crianças obesas, portadoras de deficiência congênita de leptina, quando tratadas com a proteína, reverteram o quadro de obesidade. Outras tentativas buscando a redução da ingestão alimentar e da massa corporal humana, por meio da administração diária de leptina, demonstraram-se ineficazes. Resultados satisfatórios foram obtidos somente a partir da oferta de doses muito elevadas ${ }^{8}$. De outro modo, a presença de teores circulantes elevados de leptina, indica que resistência à proteína desempenha papel importante na obesidade $^{9}$ e o entendimento do mecanismo responsável pela resistência tem sido objeto de vários estudos. Nesse sentido, verificou-se que a ocorrência de mutações nos receptores de leptina imprime, tanto em roedores como em humanos, resistência aos efeitos do controle da ingestão de alimentos atribuídos a essa adipocitocina.

Estudos acerca da obesidade humana sugerem que a resistência poderia resultar ainda de um defeito no transporte da leptina ao sistema nervoso central ${ }^{10}$ ou também um defeito pós-receptor, levando a uma falha na ativação dos mediadores neuroendócrinos reguladores do peso corporal $^{8}$. A base molecular da resistência à leptina, exceto mutações no receptor, permanece por ser determinada. Adicionalmente, a verificação da presença da proteína em animais e indivíduos sem sobrepeso, estendeu o reconhecimento da existência de uma importante função fisiológica da leptina no controle do balanço energético, da massa corporal bem como da função neuroendócrina ${ }^{11}$. Várias outras ações fisiológicas vêm sendo atribuídas à leptina, entre elas, envolvi- 
mento na função reprodutiva ${ }^{12}$, hematopoiese ${ }^{12}$, angiogênese ${ }^{13}$, resposta imune ${ }^{14}$ e formação óssea ${ }^{15}$. De todo modo, reconhece-se que a região do cérebro associado ao controle central do balanço energético constitui o maior alvo dessa adipocitocina.

A leptina interage com diferentes sistemas neuroendócrinos centrais, envolvidos no controle da ingestão de alimentos, incluindo, por exemplo, o neuropeptídio Y (NPY), sintetizado no núcleo arqueado do hipotálamo, que constitui um potente estimulador da ingestão de alimentos ${ }^{16}$. Tanto deficiência como resistência à leptina causam superexpressão de NPY hipotalâmico, implicado na hiperfagia da obesidade ${ }^{17}$. Outro sistema regulador da homeostase energética envolve a insulina hipotalâmica. Concentração fisiológica de leptina inibe a secreção de insulina em ratos, cujo efeito parece ser mediado indiretamente via ação do sistema nervoso central' ${ }^{18}$. Mais uma vez, tanto deficiência quanto resistência à leptina, em roedores obesos, está acompanhada de severa resistência à insulina.

Essa condição é rapidamente melhorada pela administração de leptina em ratos deficientes, até mesmo antes da redução do peso corporal. Muitos estudos têm demonstrado que a leptina tem ação direta e inibitória sobre a secreção de insulina $^{19}$. A leptina poderia inibir a secreção de insulina pela ativação dos canais de potássio dependentes de ATP ou via interação com a sinalização da proteína AMP quinase A. Evidências adicionais sugerem que a leptina promove a oxidação de triacilgliceróis do tecido adiposo e reduz a acumulação de gordura, inibindo a lipogênese e estimulando a lipólise ${ }^{20}$. A administração de leptina no músculo esquelético ativa a AMPK (5'-AMP proteína quinase ativada), levando à inibição da acetil-coenzima $A$ carboxilase e a subseqüente estimulação da oxidação de ácidos graxos. A depleção de lipídeos no interior da célula muscular leva ao aumento da sensibilidade à insulina ${ }^{21}$. Nesse sentido, a administração de leptina tem sido proposta como um tratamento alternativo para melhorar a sensibilidade à insulina nos indivíduos diabéticos, entre os quais prevalece a ocorrência de teores reduzidos de leptina ${ }^{22}$. Adicionalmente, também foi demonstrado que a ação central da leptina mostra-se capaz de proporcionar glicemia normal, independentemente da insulina pancreática ${ }^{23}$.

A leptina pode exercer, ainda, efeito hipoglicemiante, resultante da maior utilização periférica de glicose e do aumento da sensibilidade insulínica. A superexpressão de leptina no tecido hepático, obtida em modelo experimental, utilizando camundongos transgênicos, desenvolvido com a finalidade de explorar, in vivo, as conseqüências metabólicas do aumento da leptinemia, semelhante àquela verificada entre indivíduos obesos, promoveu aumento do metabolismo da glicose, com marcante decréscimo dos estoques de glicogênio hepático, acompanhado de ativação da sinalização insulínica no músculo esquelético e nos hepatócitos ${ }^{24}$. De qualquer modo, entre indivíduos obesos, deficientes de leptina (com mutação no gene $O b$ ), a homeostase glicêmica não se encontra alterada 25 .

\section{Adiponectina}

Em meados de 1990, mais uma proteína expressa exclusivamente pelo tecido adiposo, demonstrando importantes efeitos sobre o metabolismo, foi identificada e denominada adiponectina. Em contraste à maioria das proteínas secretada pelos adipócitos, sua expressão diminui à medida que o tecido adiposo aumenta ${ }^{26}$ e sua concentração no soro encontra-se reduzida em indivíduos e roedores obesos ou resistentes à insulina. Foi sugerido que indivíduos com concentrações circulantes elevadas de adiponectina estão menos sujeitos ao desenvolvimento de diabetes tipo II, quando comparados àqueles com concentrações reduzidas ${ }^{27}$.

Efeitos anti-aterogênicos também têm sido atribuídos a essa adipocitocina. Adiponectina demonstra capacidade de inibir a adesão de monócitos ao endotélio vascular, a transformação de macrófagos em foam cells e a expressão de 
moléculas de adesão, suprimindo, inclusive, a expressão de TNF- $\alpha$ induzida por essas moléculas de adesão ${ }^{28,29}$. Concentração plasmática reduzida de adiponectina também se associa significantemente com risco de doenças cardiovasculares em humanos ${ }^{30}$. Nesse sentido, a adiponectina circulante parece proteger o endotélio vascular contra a maioria dos processos envolvidos na etiopatogenia da aterosclerose. Em indivíduos que apresentaram uma redução nos teores circulantes da adipocitocina, foram observadas várias disfunções metabólicas associadas. Grande parte dos indivíduos manifesta diabetes, hipertensão, dislipidemia e aterosclerose ${ }^{30}$, sugerindo a existência de associação entre hipoadiponectinemia e o estabelecimento da síndrome metabólica. Concentrações diminuídas de adiponectina plasmática também mostraram associação com aumento do risco de câncer de mama. Nesse caso, ainda não são conhecidos os mecanismos envolvidos $^{31}$.

Manipulações nutricionais e terapêuticas que melhoram a sensibilidade à insulina, tais como restrição energética, perda de peso e tratamento com TZDs, aumentam a expressão gênica de adiponectina, bem como o seu conteúdo circulante. Contrariamente, TNF- $\alpha$ e IL- 6 são potentes inibidores da expressão e secreção de adiponectina. Recentemente, verificou-se que a administração de adiponectina recombinante reduziu a glicemia e melhorou a resistência à insulina em modelos de ratos obesos ou diabéticos. O efeito da adiponectina na melhoria da sensibilidade à insulina é mediado, pelo menos em parte, por um aumento da oxidação de gordura por ativação da enzima adenina monofosfato quinase, em músculos esqueléticos, semelhante à ação sinalizada pela própria insulina. Além disso, adiponectina também ativa essa enzima no fígado, resultando na redução da produção de glicose hepática32.

\section{Resistina}

Constitui adipocitocina recentemente identificada, pertencente a uma família de pro- teínas ricas em cisteína, encontradas em regiões de inflamação. A resistina é expressa especificamente no tecido adiposo branco e sua secreção está fortemente relacionada à resistência à insulina ${ }^{33}$, verificando-se aumento nas concentrações de resistina em animais obesos e diabéticos. Há ainda evidências de que a obesidade induzida por dietas hiperlipídicas, bem como mutações do gene da leptina estão associadas com elevadas concentrações circulantes de resistina ${ }^{34}$. Resistina administrada intraperitonealmente eleva a glicemia plasmática e induz a uma significante resistência insulínica hepática. Outro estudo envolvendo a administração de resistina recombinante em ratos promoveu resistência à insulina sistêmica e diminuiu o transporte de glicose estimulado pela insulina, enquanto a administração do anticorpo anti resistina produziu efeito contrário ${ }^{33}$. Adicionalmente, anticorpos anti-resistina diminuem a glicemia e melhoram a sensibilidade à insulina em ratos obesos $^{35}$. Estudos em humanos ainda são muito controversos. A expressão gênica de resistina pelo tecido adiposo não foi encontrada em indivíduos magros. No tecido adiposo de indivíduos obesos, embora essa adipocitocina tenha sido identificada, não foi verificada correlação entre a sua expressão gênica e massa corporal, adiposidade e resistência à insulina ${ }^{35}$. O envolvimento da resistina no processo inflamatório crônico, associado à obesidade, constitui hipótese alternativa capaz de justificar a presença dessa proteína, integrante de uma família de proteínas encontradas em regiões inflamatórias, no tecido adiposo de indivíduos obesos $^{36}$.

Há expectativa de que a identificação do receptor de resistina e das vias de sinalização resultantes da elevada ou reduzida expressão de resistina em ratos transgênicos, proporcionem melhor esclarecimento acerca das funções biológicas dessa adipocitocina.

\section{Proteína estimuladora de acilação}

Produzida pelo tecido adiposo, a proteína estimuladora de acilação (ASP) constitui adipo- 
citocina derivada da interação dos compostos conhecidos como complemento C3, fator B e adipsina. Essa proteína vem sendo reconhecida como um estimulante da síntese e acumulação de triacilglicerol no tecido adiposo, efeitos alcançados a partir da ação da adipocitocina em diferentes processos celulares. Embora os receptores e mecanismos de sinalização, mediados pela ASP, ainda sejam desconhecidos, há evidências de que a proteína esteja envolvida na ativação do transporte de glicose, no aumento da reesterificação de ácidos graxos e na inibição da lipólise ${ }^{37}$. Entretanto, alguns estudos com indivíduos obesos não revelaram aumento significante na concentração plasmática de $\mathrm{ASP}^{37}$. De outro modo, durante o jejum ou perda de peso, existem evidências da ocorrência de redução nos teores sanguíneos de ASP.

Maslowska et al. ${ }^{38}$ mostraram que a elevação da secreção de ASP pelos adipócitos acompanha o aumento das concentrações sanguíneas de insulina, sugerindo que a insulina poderia constituir mediador da redução da produção de ASP durante um período de jejum ou restrição energética bem como da elevação dos teores de ASP após as refeições. Adicionalmente, há evidências de que lipídeos circulantes também estimulam a expressão de ASP, após ingestão de grande quantidade desses nutrientes. Estudo utilizando cultura de adipócitos humanos, revelou aumento na secreção de ASP induzido por quilomícrons ${ }^{39}$.

Comuzzie et al. ${ }^{40}$, em 2001, demonstraram a existência de correlação entre as concentrações plasmáticas de ASP e os genes que controlam os teores circulantes de colesterol total, LDL-c e triacilgliceróis, solidificando a hipótese de que a ASP possa constituir elemento regulador do metabolismo lipídico em humanos. Permanece sob investigação se a elevação do conteúdo sanguíneo de ASP reflete aumento da atividade dessa adipocitocina ou representa um quadro de resistência à sua própria ação. A resistência à ASP poderia promover o redirecionamento do fluxo lipídico em direção ao fígado ${ }^{37}$. Foi demonstrado que a ausência de ASP resultou em moderada redução de tecido adiposo, associada à diminuição dos estoques de triacilgliceróis bem como da massa corporal. Adicionalmente, os ratos deficientes de ASP pareceram mais sensíveis à insulina, provavelmente devido a sua menor adiposidade corporal ${ }^{41}$. O conjunto de achados disponíveis aponta para o reconhecimento de que a redução nas concentrações de ASP pode constituir importante tratamento na obesidade.

\section{Fator de necrose tumoral}

O tecido adiposo produz várias citocinas pró-inflamatórias incluindo-se entre estas, o fator de necrose tumoral (TNF- $\alpha$ ). Representa um produto dos macrófagos relacionado a distúrbios metabólicos e processos crônicos de inflamação ${ }^{42}$. As primeiras informações acerca das ações biológicas associadas ao TNF- $\alpha$ definiam um envolvimento na resistência à insulina, perda de peso corporal e anorexia. O aumento da lipólise decorreria do estímulo proporcionado pelo TNF- $\alpha$ na expressão da enzima lipase hormônio sensível $(\mathrm{HSL})$, levando à diminuição da atividade da lipase lipoprotéica (LPL). Entretanto, investigações mais recentes têm revelado vínculo molecular mais estreito entre o TNF- $\alpha$ e a obesidade, verificando-se que a expressão de TNF- $\alpha$ está aumentada na obesidade e diminui com a perda de peso corporal, melhorando a sensibilidade à insulina ${ }^{43}$.

Há ainda referências de que triacilgliceróis e ácidos graxos livres exerçam forte influência na indução da expressão de TNF- $\alpha$. Roedores tratados com dieta hiperlipídica apresentaram aumento significativo da expressão de TNF- $\alpha$ e alteração da via de sinalização insulínica in vivo ${ }^{44}$. Anticorpos anti TNF- $\alpha$ melhoram a sensibilidade à insulina em roedores obesos, enquanto que animais deficientes de TNF- $\alpha$, mesmo quando submetidos a dieta hiperlipídica, apresentam-se "protegidos" em relação ao desenvolvimento de obesidade com resistência à insulina.

Há ainda indícios de que o aumento da expressão gênica de TNF- $\alpha$ no tecido adiposo bem como a sua elevada concentração plasmática 
poderiam induzir à obesidade, em parte, por alterar a liberação na circulação de outras adipocitocinas, como o inibidor do ativador de plasminogênio-I (PAI-I) e a adiponectina. Ratificam essa hipótese resultados de experimentos envolvendo ratos tratados com TZDs. Foi verificada diminuição da expressão gênica de TNF- $\alpha$ no tecido adiposo bem como sensibilidade inalterada à insulina neste tecido. Além disso, ocorreu aumento da expressão de PAI-I e diminuição da adiponectina no tecido adiposo branco ${ }^{45}$.

\section{Interleucina-6}

O tecido adiposo humano produz quantidades elevadas de interleucina-6 (IL-6). Essa secreção pode representar cerca de $10 \%$ a $30 \%$ dos teores circulantes dessa citocina multifuncional, também produzida por outros diferentes tipos de células ${ }^{46}$. O tecido adiposo visceral produz e secreta três vezes mais IL-6 do que o subcutâneo ${ }^{47}$. O conteúdo plasmático de IL-6 apresenta-se positivamente correlacionado ao aumento da massa corporal e, inversamente, à sensibilidade à insulina. TNF- $\alpha$, glicocorticóides e catecolaminas representam alguns importantes moduladores da expressão de IL-6 pelo tecido adiposo ${ }^{47}$. De acordo com Nonogaki et al. ${ }^{48}$, o impacto metabólico produzido pelo aumento da expressão de IL-6 nos depósitos corporais de gordura, pode ser de crucial importância na patogenia da obesidade. O conteúdo plasmático aumentado de IL-6 poderia estimular a síntese hepática de triacilglicerol, contribuindo para a hipertrigliceridemia associada à obesidade visceral. Indivíduos apresentando doença cardiovascular mostraram teores circulantes elevados de IL-6. Haddy et al. ${ }^{49}$, em 2003, sugeriram que a IL-6 poderia constituir fator de interligação entre a aterosclerose e o processo inflamatório, dadas a demonstração de associação negativa entre IL-6 e HDL-c e a forte associação positiva entre essa citocina e mediadores inflamatórios tais como, o TNF- $\alpha$ e as moléculas de adesão ICAM-1 e selectina.

Há indícios recentes de que a IL-6 exerça ação direta sobre a sensibilidade à insulina, alterando a sinalização insulínica em hepatócitos, mediante a inibição do receptor de insulina dependente de autofosforilação, promovendo, desse modo, resistência à ação do hormônio no tecido. Paradoxalmente, estudos realizados com roedores mostraram que, na deficiência de IL-6, pode ocorrer uma indução de obesidade com intolerância à glicose $e^{48}$, e que a administração intracerebroventricular dessa citocina pode diminuir a gordura corporal ${ }^{50}$. O conjunto desses achados sugere que a IL-6 pode agir de formas distintas, dependendo da sua concentração orgânica, tanto nos tecidos periféricos quanto no sistema nervoso central, influenciando o peso corporal, a homeostase energética e a sensibilidade insulínica.

\section{A DIPOCITOCINASE SISTEMA VASCULAR}

\section{Inibidor do ativador de plasminogênio-I}

A deterioração do sistema de fibrinólise faz parte das complicações cardiovasculares da obesidade. Esse defeito tem sido relacionado às elevadas concentrações do PAI-I. Atribui-se ao PAI-I o papel de principal inibidor fisiológico da fibrinólise, na medida em que apresenta a capacidade de inibir o precursor da plasmina, cuja ação no processo de rompimento das redes de fibrina, evita a formação do trombo ${ }^{51}$. Há referências acerca da relação entre o aparecimento de eventos tromboembólicos e concentrações aumentadas de PAI-I. Entre os inúmeros mecanismos que relacionam obesidade e o desenvolvimento de doenças cardiovasculares, as alterações no sistema de fibrinólise parecem se destacar. Na obesidade, o tecido adiposo branco constitui a principal fonte geradora de PAI-I, principalmente a gordura visceral. Pré adipócitos, mais numerosos no tecido adiposo visceral do que no subcutâneo, contribuem mais para a produção de PAI-I em humanos ${ }^{52}$. Há evidências de que a insulina e o fator de crescimento transformador - $\beta$ induzem a síntese de PAl-I no tecido adiposo. Evidências adicionais apontam efeito estimulador também para o TNF- $\alpha$ e a $\mathrm{IL}-1$, o que possivelmente contribui para o aumen- 
to das concentrações de PAI-I verificado nos indivíduos obesos e resistentes à insulina ${ }^{53}$.

Além de participar no processo de regulação da fibrinólise, o PAI-I também tem sido reconhecido capaz de influenciar a migração celular e a angiogênese ${ }^{54}$. Há descrição de que, no tecido adiposo branco, o PAI-I poderia prejudicar a migração de pré adipócitos, afetando o crescimento desse tecido ${ }^{55}$. Nesse sentido, ratos submetidos a dieta hiperlipídica, que sofreram uma manipulação genética gerando um aumento da expressão gênica de PAl-I pelos adipócitos, atenuaram a hipertrofia do tecido adiposo ${ }^{56}$. Em conclusão, apesar de a maior expressão de PAI-I promover efeito desfavorável na fibrinólise, o aumento dessa adipocitocina mostra-se capaz de proteger o organismo contra o crescimento excessivo do tecido adiposo, pelo menos quando associado a dieta hiperenergética.

\section{Angiotensinogênio}

A hipertensão é uma complicação freqüente da obesidade e um importante fator de risco para o desenvolvimento de doenças cardiovasculares. Estudos epidemiológicos mostram uma correlação positiva significante entre pressão sanguínea e teores circulantes de angiotensinogênio ${ }^{57}$. O angiotensinogênio constitui substrato da renina no sistema renina-angiotensina, sendo convertido em angiotensinogênio I, um precursor da angiotensina II, que influencia a diferenciação de adipócitos. Embora a produção de angiotensinogênio ocorra principalmente no fígado, o tecido adiposo é considerado uma importante fonte extra-hepática, contribuindo, possivelmente, para a elevação dos teores circulantes em indivíduos obesos. A expressão de angiotensinogênio pelo tecido adiposo está aumentada na obesidade e, diferentemente da expressão hepática, é regulada por fatores nutricionais. Nesse sentido, durante o jejum, verifica-se diminuição da expressão da adipocitocina, enquanto que após a ingestão de alimento, observa-se a sua elevação ${ }^{58}$. Experimentos envolvendo ratos geneticamente manipulados têm buscado esclarecer a importância fisiopatológica da produção de angiotensinogênio pelo tecido adiposo. A introdução do gene que expressa angiotensinogênio, especificamente no tecido adiposo branco, resulta em concentração plasmática aumentada de angiotensinogênio, hipertensão e aumento da massa adiposa. Ratos deficientes em angiotensinogênio manifestam hipotensão aliada à diminuição da massa adiposa A indução do aumento da expressão de angiotensinogênio pelo tecido adiposo, promove o restabelecimento da pressão sanguínea e da massa adiposa, as quais tendem a aumentar, após um determinado período de tempo ${ }^{59}$.

Ratos deficientes em angiotensinogênio demonstram ainda apresentar certa "proteção" em relação ao desenvolvimento da obesidade, mesmo quando submetidos a dietas hiperenergéticas. Esses achados experimentais permitem supor que em indivíduos obesos ocorra produção elevada de angiotensinogênio pelo tecido adiposo, aumentando seus teores circulantes, o que favoreceria a hipertensão. O aumento da produção de angiotensinogênio também poderia contribuir para um aumento da massa adiposa. Nesse caso, o efeito indutor tem sido atribuído à ação local da angiotensina II como fator importante na diferenciação de adipócitos ${ }^{60}$.

No Quadro 1 é apresentado o resumo das principais adipocitocinas e seus efeitos.

\section{O N CLUS Ã O}

A identificação do tecido adiposo como órgão endócrino conferiu-lhe o status de tecido fundamental produtor de uma complexa rede de fatores capazes de influenciar inúmeros processos metabólicos e fisiológicos. Algumas adipocitocinas, como a leptina e a adiponectina, exercem efeitos benéficos sobre o balanço energético, a ação insulínica e a proteção vascular. Contrariamente, a produção excessiva de outras adipocitocinas pode tornar-se deletéria ao organismo. TNF- $\alpha$, IL-6 e resistina podem deteriorar a ação da insulina, enquanto PAl-I e angiotensinogênio envolvem-se em complicações vasculares associadas à obesidade. 
Quadro 1. Adipocitocinas secretadas pelo tecido adiposo.

\begin{tabular}{llc}
\hline Citocina & \multicolumn{1}{c}{ Função / Efeito } & Referência \\
\hline Adiponectina & Influência na sensibilização insulínica e propriedades anti-aterogênicas & $23,24,25,27$ \\
Angiotensinogênio & $\begin{array}{l}\text { Precursor da angiotensina II, regulador da pressão sanguínea e influência na adiposi- } \\
\text { dade }\end{array}$ & $53,55,56$ \\
ASP & Influência na síntese de triacilglicerol no tecido adiposo & $32,35,36$ \\
IL-6 & Mediador do processo inflamatório e influência no metabolismo lipídico & $42,43,44,46$ \\
Leptina & Sinalização cerebral do estoque de gordura corporal, influência na sensibilização & $5-10,12,18$, \\
& insulínica, regulação do apetite e gasto energético & \\
PAl-1 & Potente inibidor do sistema de fibrinólise & $47,48,49,50,51$ \\
Resistina & Influência no desenvolvimento à resistência insulínica & $28,29,30$ \\
TNF- $\alpha$ & Interferência na sinalização insulínica e possível causa da resistência à insulina na & $37,38,40,41$ \\
& obesidade & \\
\hline
\end{tabular}

PAI-I: inibidor do ativador de plasminogênio-I; ASP: proteína estimuladora de acilação; TNF- $\alpha$ : fator de necrose tumoral; IL-6: Intereleucina-6.

Parece promissora a perspectiva de desenvolvimento de novos medicamentos, com base nos conhecimentos já disponíveis acerca das ações metabólicas dessas adipocitocinas, especialmente destinados ao tratamento de doenças associadas ao desequilíbrio do tecido adiposo branco, como a obesidade. A possibilidade de produção de impacto positivo sobre a sensibilidade dos tecidos periféricos à ação da insulina, bem como de proporcionar proteção contra o estabelecimento da aterosclerose, justificaria o investimento científico e financeiro destinado à ampliação dos conhecimentos acerca dessas citocinas, assim como de sua aplicação terapêutica.

\section{COLABORADORES}

D.E.D. GUIMARÃES, F.L.C. SARDINHA, D.M. MIZURINI e M.G.T. CARMO colaboraram na concepção e redação do artigo.

\section{REFERÊ N CIAS}

1. Havel PJ. Update on adipocyte hormones: regulation of energy balance and carbohydrate/ lipid metabolism. Diabetes. 2004; 53(Suppl 1): S143-51.

2. Hauner $\mathrm{H}$. The new concept of adipose tissue function. Physiol Behav. 2004; 83(4):653-8.

3. Dusserre $E$, Moulin P, Vidal H. Differences in mRNA expression of the proteins secreted by the adipocytes in human subcutaneous and visceral adipose tissues. Biochim Biophys Acta. 2000; 1500(1):88-96.

4. Halaas JL, Gajiwala KS, Maffei M, Cohen SL, Chait BT, Rabinowitz D, et al. Weight-reducing effects of the plasma protein encoded by the obese gene. Science. 1995; 269(5223):543-6.

5. Montague CT, Farooqi IS, Whitehead JP, Soos MA, Rau H, Wareham NJ, et al. Congenital leptin deficiency is associated with severe early-onset obesity in humans. Nature. 1997; 387(6636): 903-8.

6. Maffei M, Stoffel M, Barone M, Moon B, Dammerman $M$, Ravussin $E$, et al. Absence of mutations in the human $\mathrm{OB}$ gene in obese/diabetic subjects. Diabetes. 1996; 45(5):679-82.

7. Farooqi IS, Matarese G, Lord GM, Keogh JM, Lawrence E, Agwu C, et al. Beneficial effects of leptin on obesity, $\mathrm{T}$ cell hyporesponsiveness, and neuroendocrine/metabolic dysfunction of human congenital leptin deficiency. J Clin Invest. 2002; 110(8):1093-103.

8. Kalra SP. Circumventing leptin resistance for weight control. Proc Natl Acad Sci USA. 2001; 98(8): 4279-81.

9. Maffei M, Halaas J, Ravussin E, Pratley RE, Lee GH, Zhang $Y$, et al. Leptin levels in human and rodent: measurement of plasma leptin and ob RNA in obese and weight-reduced subjects. Nat Med. 1995; 1(11):1155-61.

10. Caro JF, Kolaczynski JW, Nyce MR, Ohannesian JP, Opentanova I, Goldman WH, et al. Decreased cerebrospinal-fluid/serum leptin ratio in obesity: a possible mechanism for leptin resistance. Lancet. 1996; 348(9021):159-61. 
11. Ahima RS, Flier JS. Leptin. Ann Rev Physiol. 2000; 62:413-37.

12. Cioffi JA, Shafer AW, Zupancic TJ, Smith-Gbur J, Mikhail A, Platika D, et al. Novel B219/OB receptor isoforms: possible role of leptin in hematopoiesis and reproduction. Nat Med. 1996; 2(5):585-9.

13. Sierra-Honigmann MR, Nath AK, Murakami C, Garcia-Cardena G, Papapetropoulos A, Sessa WC, et al. Biological action of leptin as an angiogenic factor. Science. 1998; 281(5383):1683-6.

14. Lord GM, Matarese G, Howard JK, Baker RJ, Bloom SR, Lechler RI. Leptin modulates the T-cell immune response and reverses starvation-induced immunosuppression. Nature. 1998; 394(6696): 897-901.

15. Ducy $P$, Amling $M$, Takeda $S$, Priemel M, Schilling $A F$, Beil $F T$, et al. Leptin inhibits bone formation through a hypothalamic relay: a central control of bone mass. Cell. 2000; 100(2):197-207.

16. Campfield LA, Smith FJ, Guisez Y, Devos R, Burn P. Recombinant mouse OB protein: evidence for a peripheral signal linking adiposity and central neural networks. Science. 1995; 269(5223): 546-9.

17. Schwartz MW, Baskin DG, Bukowski TR, Kuijper JL, Foster D, Lasser G, et al. Specificity of leptin action on elevated blood glucose levels and hypothalamic neuropeptide $\mathrm{Y}$ gene expression in ob/ob mice. Diabetes. 1996; 45(4):531-5.

18. Muzumdar R, Ma X, Yang X, Atzmon G, Bernstein J, Karkanias G, et al. Physiologic effect of leptin on insulin secretion is mediated mainly through central mechanisms FASEB J. 2003; 17(9):1130-2.

19. Seufert J, Kieffer TJ, Leech CA, Holz GG, Moritz W, Ricordi C, et al. Leptin suppression of insulin secretion and gene expression in human pancreatic islets: implications for the development of adipogenic diabetes mellitus. J Clin Endocrinol Metab. 1999; 84(2):670-6.

20. Ahren B, Havel PJ. Leptin inhibits insulin secretion induced by cellular CAMP in a pancreatic $B$ cell line (INS-1 cells). Am J Physiol. 1999; 277(4 Pt 2): R959-66.

21. Greco AV, Mingrone G, Giancaterini A, Manco M, Morroni $M$, Cinti $S$, et al. Insulin resistance in morbid obesity: reversal with intramyocellular fat depletion. Diabetes. 2002; 51(1):144-51.

22. Shimomura I, Hammer RE, Ikemoto S, Brown MS, Goldstein JL. Leptin reverses insulin resistance and diabetes mellitus in mice with congenital lipodystrophy. Nature. 1999; 401(6748):73-6.

23. Ueno N, Inui A, Kalra PS, Kalra SP. Leptin transgene expression in the hypothalamus enforces euglycemia in diabetic, insulin-deficient nonobese Akita mice and leptin-deficient obese ob/ob mice. Peptides. 2006; 27(9):2332-42.
24. Ogawa Y, Masuzaki H, Hosoda K, Aizawa-Abe M, Suga J, Suda $M$, et al. Increased glucose metabolism and insulin sensitivity in transgenic skinny mice overexpressing leptin. Diabetes. 1999; 48(9):1822-9.

25. Clement K, Vaisse C, Lahlou N, Cabrol S, Pelloux V, Cassuto $D$, et al. A mutation in the human leptin receptor gene causes obesity and pituitary dysfunction. Nature. 1998; 392(6674):398-401.

26. Ouchi N, Kihara S, Arita Y, Maeda K, Kuriyama H, Okamoto $Y$, et al. Novel modulator for endothelial adhesion molecules: adipocyte-derived plasma protein adiponectin. Circulation. 1999; 100(25): 2473-6.

27. Spranger J, Kroke A, Mohlig M, Bergmann MM, Ristow $M$, Boeing $H$, et al. Adiponectin and protection against type 2 diabetes mellitus. Lancet. 2003; 361(9353):226-8.

28. Goldstein BJ, Scalia R. Adiponectin: a novel adipokine linking adipocytes and vascular function. J Clin Endocrinol Metab. 2004; 89(6):2563-8.

29. Fantuzzi G. Adipose tissue, adipokines, and inflammation. J Allergy Clin Immunol. 2005; 115(5):911-9.

30. Funahashi T, Matsuzawa Y, Kihara S. Adiponectin as a potential key player in metabolic syndrome Insights into atherosclerosis, diabetes and cancer. Int Congress Series. 2004; 1262:368-71.

31. Miyoshi Y, Funahashi T, Kihara S, Taguchi T, Tamaki $Y$, Matsuzawa $Y$, et al. Association of serum adiponectin levels with breast cancer risk. Clin Cancer Res. 2003; 9(15):5699-704.

32. Yamauchi T, Kamon J, Minokoshi $Y$, Ito $Y$, Waki $H$, Uchida $S$, et al. Adiponectin stimulates glucose utilization and fatty-acid oxidation by activating AMP-activated protein kinase. Nat Med. 2002; 8(11):1288-95.

33. Steppan CM, Bailey ST, Bhat S, Brown EJ, Banerjee $\mathrm{RR}$, Wright $C M$, et al. The hormone resistin links obesity to diabetes. Nature. 2001; 409(6818): 307-12.

34. Savage DB, Sewter CP, Klenk ES, Segal DG, Vidal-Puig A, Considine RV, et al. Resistin/Fizz3 expression in relation to obesity and peroxisome proliferator-activated receptor-gamma action in humans. Diabetes. 2001; 50(10):2199-202.

35. Janke J, Engeli S, Gorzelniak K, Luft FC, Sharma AM. Resistin gene expression in human adipocytes is not related to insulin resistance. Obes Res. 2002; 10(1):1-5.

36. Gomez-Ambrosi J, Fruhbeck G. Do resistin and resistin-like molecules also link obesity to inflammatory diseases? Ann Intern Med. 2001; 135(4):306-7.

37. Cianflone K, Xia Z, Chen LY. Critical review of acylation-stimulating protein physiology in 
humans and rodents. Biochim Biophys Acta. 2003; 1609(2):127-43.

38. Maslowska M, Scantlebury T, Germinario R, Cianflone K. Acute in vitro production of acylation stimulating protein in differentiated human adipocytes. J Lipid Res. 1997; 38(1):1-11.

39. Scantlebury T, Maslowska M, Cianflone K. Chylomicron-specific enhancement of acylation stimulating protein and precursor protein C3 production in differentiated human adipocytes. J Biol Chem. 1998; 273(33):20903-9.

40. Comuzzie AG, Cianflone K, Martin LJ, Zakarian R, Nagrani G, Almasy L, et al. Serum levels of acylation stimulating protein (ASP) show evidence of a pleiotropic relationship with total cholesterol, LDL, and triglycerides and preliminary evidence of linkage on chromosomes 5 and 17 in Mexican Americans. Obes Res. 2001; 9:103S.

41. Murray I, Havel PJ, Sniderman AD, Cianflone K. Reduced body weight, adipose tissue, and leptin levels despite increased energy intake in female mice lacking acylation-stimulating protein. Endocrinology. 2000; 141(3):1041-9.

42. Coppack SW. Pro-inflammatory cytokines and adipose tissue. Proc Nutr Soc. 2001; 60(3):349-56.

43. Fruhbeck G, Gomez-Ambrosi J, Muruzabal FJ, Burrell MA. The adipocyte: a model for integration of endocrine and metabolic signaling in energy metabolism regulation. Am J Physiol Endocrinol Metab. 2001; 280(6):E827-47.

44. Morin CL, Eckel RH, Marcel T, Pagliassotti MJ. High fat diets elevate adipose tissue-derived tumor necrosis factor-alpha activity. Endocrinology. 1997; 138(11):4665-71.

45. Ruan H, Miles PD, Ladd CM, Ross K, Golub TR, Olefsky JM, et al. Profiling gene transcription in vivo reveals adipose tissue as an immediate target of tumor necrosis factor-alpha: implications for insulin resistance. Diabetes. 2002; 51(11): 3176-88.

46. Van Snick J. Interleukin-6: an overview. Ann Rev Immunol. 1996; 8:253-78.

47. Fried SK, Bunkin DA, Greenberg AS. Omental and subcutaneous adipose tissues of obese subjects release interleukin-6: depot difference and regulation by glucocorticoid. J Clin Endocrinol Metab. 1998; 83(3):847-50.

48. Nonogaki K, Fuller GM, Fuentes NL, Moser AH, Staprans I, Grunfeld C, et al. Interleukin-6 stimulates hepatic triglyceride secretion in rats. Endocrinology. 1995; 136(5):2143-9.

49. Haddy N, Sass C, Droesch S, Zaiou M, Siest G, Ponthieux A, et al. IL-6, TNF-alpha and atherosclerosis risk indicators in a healthy family population: the STANISLAS cohort. Atherosclerosis. 2003; 170(2):277-83.
50. Wallenius K, Wallenius $V$, Sunter D, Dickson SL, Jansson JO. Intracerebroventricular interleukin-6 treatment decreases body fat in rats. Biochem Biophys Res Commun. 2002; 293(1):560-5.

51. Juhan-Vague I, Alessi MC. PAl-1, obesity, insulin resistance and risk of cardiovascular events. Thromb Haemost. 1997; 78(1):656-60.

52. Bastelica D, Morange $P$, Berthet $B$, Borghi $H$, Lacroix $O$, Grino $M$, et al. Stromal cells are the main plasminogen activator inhibitor-1-producing cells in human fat: evidence of differences between visceral and subcutaneous deposits. Arterioscler Thromb Vasc Biol. 2002; 22(1):173-8.

53. Samad F, Loskutoff DJ. Tissue distribution and regulation of plasminogen activator inhibitor- 1 in obese mice. Mol Med. 1996; 2(5):568-82.

54. Birgel M, Gottschling-Zeller H, Rohrig K, Hauner $\mathrm{H}$. Role of cytokines in the regulation of plasminogen activator inhibitor-1 expression and secretion in newly differentiated subcutaneous human adipocytes. Arterioscler Thromb Vasc Biol. 2000; 20(6):1682-7.

55. Crandall DL, Busler DE, McHendry-Rinde B, Groeling TM, Kral JG. Autocrine regulation of human preadipocyte migration by plasminogen activator inhibitor-1. J Clin Endocrinol Metab. 2000; 85(7):2609-14.

56. Schafer K, Fujisawa K, Konstantinides S, Loskutoff DJ. Disruption of the plasminogen activator inhibitor 1 gene reduces the adiposity and improves the metabolic profile of genetically obese and diabetic ob/ob mice. FASEB J. 2001; 15(10):1840-2.

57. Massiera F, Bloch-Faure M, Ceiler D, Murakami K, Fukamizu A, Gasc JM, et al. Adipose angiotensinogen is involved in adipose tissue growth and blood pressure regulation. FASEB J. 2001; 15(14):2727-9.

58. Einstein FH, Atzmon G, Yang XM, Ma XH, Rincon $M$, Rudin $E$, et al. Differential responses of visceral and subcutaneous fat depots to nutrients. Diabetes. 2005; 54(3):672-8.

59. Ailhaud G, Fukamizu A, Massiera F, Negrel R, SaintMarc P, Teboul M. Angiotensinogen, angiotensin II and adipose tissue development. Int J Obes Relat Metab Disord. 2000; 24(Suppl 4):S33-5.

60. Darimont C, Vassaux G, Ailhaud G, Negrel R. Differentiation of preadipose cells: paracrine role of prostacyclin upon stimulation of adipose cells by angiotensin-II. Endocrinology. 1994; 135(5): 2030-6.

Aprovado em: 18/8/2005

Versão final reapresentada em: 9/5/2007 Aprovado em: 2/5/2007 
